\title{
Recognition of Prior Learning: In Pursuit of Crediting Informal Learning for Access, Redress and Skills Development
}

\author{
Mncedisi C. Maphalala \\ University of South Africa, College of Education: \\ Department of Curriculum \& Instructional Studies, 0003, Pretoria, South Africa \\ E-mail:mphalmc@unisa.ac.za
}

\section{Doi:10.5901/mjss.2014.v5n3p395}

\begin{abstract}
Recognition of Prior Learning (RPL) recognises learning that has taken place informally, regardless of where and how it was attained. RPL acknowledges that people never stop learning, whether it takes place formally at an educational institution, or whether it happens informally. At the end of the assessment process each candidate is issued with credits for the learning that they have been able to display. These credits are linked to SAQA-registered qualifications. This is a theoretical paper which looks at the value of RPL, the challenges in its successful implementation, the RPL model and relevant assessment methods, instruments and resources necessary for RPL success.
\end{abstract}

Keywords: informal learning, assessment, evidence, certification, lifelong learning

\section{Introduction}

A number of acts have been passed since 1994, to ensure more integrated education and training system, and which foreground: access for previously disadvantaged learners to all levels of the education system, the redress of the inequalities of the past, the development of quality education across the system, and the development of the full potential of all learners. The Recognition of Prior Learning (RPL) is one of the central pillars of the National Qualification Framework (NQF), and is seen as a mechanism for facilitating access to further learning, as well as accelerated progression through qualifications for adults who may have credible learning developed in the contexts outside of the formal education system (Makole, 2010). RPL is a way of recognising what individuals already know and can do. RPL is based on the premise that people learn both inside and outside formal learning structures (including learning from work and life experiences) and this learning can be worthy of recognition and credit. RPL is used extensively by those seeking admission to a course, as advance standing for a course or credits towards a qualification. Those seeking entry to a particular field of employment, promotion or self- development can also use RPL.

The recognition of prior learning (RPL) is also described by the South African Qualifications Authority (SAQA, 1997) as the assessment of learning that has already taken place by an individual (learner) (whether through prior formal studies, work and/or life experience). This learning is evaluated by experts as being valid and reliable when measured against the learning outcomes of a specific qualification, learning programme or module/learning unit for the purpose of access to or acknowledgement within a learning programme. A more formal definition (National Standards Body Regulation no. 18787 of 28 March 1998) is: "Recognition of prior learning means the comparison of the previous learning and experience of a learner howsoever obtained against the learning outcomes required for a specific qualification, and the acceptance for purposes of qualification of that which meets the requirements.

As stated in the SAQA RPL policy (2002:11) the recognition of prior learning (RPL) is in South Africa has, unlike similar initiatives in other countries, a very specific agenda. It is meant to support transformation of the education and training system of the country. The purpose of RPL can include access to and appropriate placement at a particular level at learning institutions, the granting of advanced status, advanced standing, or the crediting and certifying of learners for the parts of the qualification where all the requirements have been met. A learner can achieve a qualification either in part (e.g. where a learner is granted credits for some Unit Standards) or fully through the process of RPL (Criteria and Guidelines for the Implementation of the RPL: 28).

The following descriptions for the abovementioned options may be helpful:

- Access: To provide ease of entry to an appropriate level of education and training for all prospective learners in a manner that facilitates progression. 
- Placement: To determine the appropriate level for learners wanting to enter education and training through a diagnostic assessment.

- Advanced status: To grant access to a level of qualification higher than the logical next level following the preceding qualification.

- Credit: To award formal, transferable credits to learning that meets part or all the requirements of a particular qualification.

- Certification: To certify credits attained for the purposes of the qualification.

RPL holds benefits for the candidate, the employer of the candidate and the institution who offers RPL. Generically speaking, RPL offers the following benefits: Costs can be kept down through co-operation between the employer and the providers of RPL; New skills can be developed; New and dormant learning pathways can be opened; Credit transfer is facilitated, provided that other learning providers recognise credits obtained through RPL; Consensus on level(s) and minimum requirements for candidates seeking credits for particular qualifications or entry to further study supports the objectives of the NQF; Learning institutions maintain their independence, since RPL procedures are generic and not dependent on specific learning content or curricula.

Despite the South African government's frequently stated role for RPL as a tool for 'social transformation' (SAQA Act, 1995; SAQA, 2002; Departments of Education and Labour, 2002) the SAQA policies give no national implementation plan to guide RPL implementation specifically in the workplace. This could be one of the reasons why there has been little implementation of RPL in South African workplaces (Deller, 2007)

This is a theoretical paper organised around the following questions:

- What is the value of RPL?

- What are the challenges in the successful implementation of RPL?

- How can South Africa implement a successful RPL model?

- What are the relevant assessment methods, instruments and resources necessary for RPL success

\section{Challenges Implementation of an RPL}

Successful implementation of an RPL service is hampered by the following challenges:

- Not all learning institutions use or recognise Unit Standard-based learning.

- There are few assessors specifically trained in assessing RPL, and no registration option as RPL assessors is currently available.

- Not many providers of learning have staff trained in the RPL processes.

- RPL is often seen as a shortcut towards obtaining qualifications. Candidates do not always realise that RPL also requires evidence of competence.

- There is no formal procedure available for recognizing and formalizing indigenous knowledge

Makole (2010) argues that one challenge for RPL is that recognized learning must be aligned with the SAQA registered unit standards or qualifications. This means that informal learning is assessed only against outcomes that are specified in the unit standards or qualifications. Learning that falls outside the specific outcomes is not assessed, or is set aside to be assessed at another stage. He further argues that candidates need to demonstrate competency in every specific outcome in a unit standard to gain credits against it. This process unfortunately identifies gaps in learning and places RPL candidates on a wider spectrum of learning pathways, making the achievement of recognized credits or qualifications an arduous task for the learner who may have had very little exposure to formal learning previously. In addition,

There are essentially two types of RPL

- The recognition of prior accredited learning

- The recognition of prior experiential learning

The first type is relatively simple to implement, provided there is a common means of assigning value to both the learner's previous qualification and the target qualification. The South African qualifications framework provides a standardised currency, via the mechanisms of level and credit, for determining the value of learning. However, the recognition of prior experiential learning is far more difficult to implement, as it involves designing instruments which will capture, measure and evaluate learning, which has been acquired experientially, and often informally, in a range of differing contexts. This is usually done by trying to match previous learning with the learning outcomes of a target qualification, and by this means translating the prior learning into the 'levels and credits' currency of the qualifications 
framework, thus enabling it to be recognised in the formal system. .

\section{The RPL Model}

The following RPL model outlines a process that can be followed by the institution to assess candidates' skills and knowledge. It traces the pathway that a candidate should follow in order to be assessed. The basic candidate-centred assessment model contains a number of steps, each having a set of specific objectives and activities. This model reflects a shift from an externally controlled assessment process to one that includes the candidate as an essential and active partner.

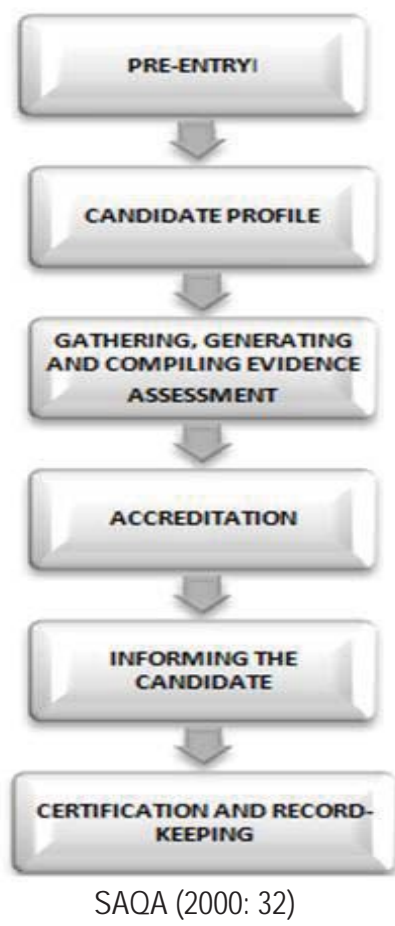

\subsection{Step 1: Pre-entry}

This step comprises the dissemination of information, links the services to others on offer, and provides adequate information to candidates to enable them to make an informed decision as to whether or not to undergo the process. It includes distributing brochures, marketing the service, meeting individual and corporate clients and collaboration between training providers and industry.

\subsection{Step 2: Candidate profile}

This comprises candidate reflection and self-assessment and is the first step towards the candidate's profile of what she can or cannot do. The candidate must clarify her expectation in seeking recognition and accreditation of prior learning and measure her skills, knowledge and competencies against standards or learning outcomes of a programme or qualification.

\subsection{Step 3: Gathering, generating and compiling evidence}

During this stage, candidates identify how they can best prove their competence and they collect and/or generate the necessary evidence. The responsibility rests on the candidate to ensure that she collects sufficient and valid evidence to 
prove that she knows and can do what she claims. The standards or learning outcomes (unit standards) must serve as a guide.

Once gathered, the evidence must be arranged and presented for submission. Most often this is requested in the form of a portfolio. However, evidence is not necessarily in paper or electronic format - it may take the form of a demonstration of skills and competencies instead of a portfolio.

\subsection{Step 4: Assessment}

Upon receiving the evidence the assessor needs to decide whether it provides sufficient, valid, authentic proof the standards or learning outcomes have been met. Should it not be sufficient, the assessor must decide on which further route to take - requesting further documentation, using a complementary assessment method (e.g. an interview in conjunction with the portfolio). The assessment is then scheduled and completed, either by an individual assessor or an assessment panel using one or more different methods of assessment. The candidate should be fully informed of what to expect - the assessment criteria and standards against which he/she will be measured must be freely and publicly available. The candidate should be given the opportunity to evaluate the process and if necessary, appeal against the process. The panel/individual makes a recommendation regarding whether or not the credit/s will be awarded. Should the credit not be awarded, it is the responsibility of the assessor to decide on what further training such as top-up training, or method of "fast-tracking" the candidate to enable him/her to present again assessment.

\subsection{Step 5: Accreditation}

The relevant decision-makers at different levels in the organisation must verify the findings and recommendations of the assessor/s and actually grant the credit. This could be either the institution itself, if it is autonomous, or it could be a national awarding body.

\subsection{Step 6: Informing the candidate}

The assessor/s must provide written feedback to the candidate. If the candidate should need or request it, he/she should be put in touch with a mentor, tutor or advisor who can provide further post-assessment guidance.

\subsection{Step 7: Certification and record keeping}

Well-documented assessment procedures and well-kept records are imperative to ensure valid processes. Most organisations have to make significant modifications to existing practices to keep clear records of each stage of the assessment. Information must be readily available at each stage of the assessment process; candidate portfolios and other evidence must be tracked throughout the system and sufficient record must be kept for a maximum period.

\section{RPL Support in the Workplace}

The support services should consciously address the invisible barriers (such as lack of access to learning and nonexposure to formal learning), to successful assessment. These (social, cultural, economic, educational and psychological) barriers can be overcome by adapting assessment and accreditation practices to suit the unique South African context. The inclusion of advisory and counselling services to complement evidence, facilitation and assessment, should meet the needs of the candidates. The candidates need relevant support in a well-managed, cost-effective process with post-assessment care. This could be achieved through well-structured and well-managed portfolio development workshops. Candidates need access to portfolio development workshops in order to select or develop the most appropriate evidence, construct his/her portfolio and prepare him/her for assessment. During portfolio preparation the RPL facilitator needs to provide information, respond to questions, review candidates' work, encourage candidates, liaise with assessors and provide candidates with fair and accurate feedback. More information on RPL is obtainable in the OBE Manual. 


\section{Assessment Methods, Instruments and Resources for RPL}

An assessment method refers to the activity that an assessor engages in as he or she assesses a learner and the learner's work. Many different methods may be used to gather evidence of a learner's knowledge, skills and understanding. The assessment activities, instruments and resources selected must be appropriate to the outcomes to be assessed, and to the assessment candidates. It also needs to have the potential for enabling valid and sufficient collection of evidence. The following are typical methods of assessment:

\subsection{Observation in the workplace}

The assessor watches the learner as he or she works in the usual workplace situation. The situation may be video-taped. The learner works at the usual speed in the usual way. The learner must be performing an appropriate task to demonstrate competencies. This method is an authentic, integral and natural part of workplace supervision. It allows for continuous assessment, disruption is minimal and it is cost-effective. It may, however, be insufficient. Some competencies cannot be easily observed or demonstrated. Assessment criteria must be clearly spelt out and assessors need to be aware of complicating factors. Good communication is essential.

\subsection{Simulation}

The tasks being assessed are recreated in a training room. The situation should be as close to the real circumstances as possible. Simulation need not be disruptive. It can be very similar to actual work conditions and is useful when direct observation is not possible. A deficiency of simulation as an assessment instrument is that it does not show real pressures or workplace situations. People may be self-conscious and it requires substantial effort to prepare. Reliability may be suspect.

\subsection{Practical demonstration}

The learner explains to and shows the assessor what he or she usually does. A practical demonstration may be done in different venues but are usually undertaken in the workplace or a training room. The subject matter can be real or simulated. These presentations can be recorded and watched again and the learner has time to prepare. It can be most effective where innovation is required. A negative characteristic of practical demonstrations is that it favours people who are articulate and confident. It may therefore be better as a supplementary source of evidence. It can also be confusing as to what is being assessed - the presentation skills or the content.

\subsection{Presentation}

A structured explanation which usually includes audio visual aids such as a white board, overhead projector slides, PowerPoint Presentation slides, and so on.

\subsection{Self-assessment}

The learner assesses himself/herself and names his or her own strengths and weaknesses. Self-assessment reveals learners self-knowledge. It is useful as preparation for assessment. It involves the individual in the work process and is useful for providing supplementary evidence. The learner becomes involved in the assessment criteria. Self-assessment may be inaccurate, since modest people tend to downplay their competence and arrogant (or ignorant) people may overplay their competence.

\subsection{Products of learners' activities}

The final products of a learner's activities are assessed. What the learner actually makes is assessed. It allows the final product to be assessed as proof of competence. It is authentic and most useful together with a supplementary form of evidence. Authenticity may be in doubt if the assessor was not present when the object was made. 


\subsection{Projects, assignments and tasks (individual or group context)}

A project or assignment may be done, either alone or in a group. It usually involves a clear set of tasks incorporating a range of competencies. It also frequently includes research, collection and analysis of data, reporting on and application of information. It may result in a final product such as a report, a presentation or an object. Projects, assignments and tasks allow for a range of competencies to be dealt with simultaneously. It allows candidates a great deal of autonomy and is especially useful where innovation is being assessed. It may, however, require massive inputs of energy and resources from both learner and assessor. Authenticity may also be difficult to establish. The topic must be carefully developed in order for evidence of assessment criteria to emerge.

\subsection{Documents linked to an activity}

These are documents kept in the normal course of the work being assessed. The documents could include minutes, memos, time sheets, schedules or log books.

\subsection{Oral discussion or interview}

A structured discussion or interview between the learner and the assessor, or between the learner and a panel. Answers (and therefore evidence) are only as good as the questions asked. It may not address real workplace issues and favours those who are more confident and articulate. Written skills are not needed and it allows for immediate feedback. Oral discussion or interviews are usually only suitable as supplementary evidence. Real workplace issues may be missed.

\subsection{Written questions and essays}

The learner responds to questions in a written form. Questions come in a variety of forms such as multiple choices, openended, matching, complete-the-gaps and so on. Essays are continuous prose, in response to a question, which are usually specified to a defined length. Written questions and essays are useful for gathering proof of factual knowledge and memory skills. It can be administered quickly and to large numbers of people simultaneously. It standardises the assessment process, is cost effective and not very time consuming. Essays in particular, may be very useful for assessing abstract thinking. Questions have limited usefulness in terms of assessing skills in analysis, synthesis and evaluation. There may be a large margin of error in results, and criteria for assessing essays may be unclear.

\subsection{Witness testimony and peer reports}

Witness testimonies are reports or endorsements by observers of the learner's activities or knowledge. Peer assessment involves colleagues at the same level as the learner giving their opinion of learners' competencies. Witness testimony and peer reports may be useful for verification purposes. It is suitable for generic competencies such as "working in a team", and "communication skills". They are simple to use but they may be biased or inaccurate. The learner may experience these as threatening and peers could find it difficult to assess a learner who is not yet competent.

\subsection{Evidence of prior achievements}

Evidence of prior achievements may include awards, certificates or actual products.

\subsection{Case studies and role-plays}

In a case study the learner responds to a detailed description of a scenario, or to a set of conditions, usually to solve a problem within that scenario. Role-plays are less passive and involve the learner acting out appropriate responses to specific situations. The assessor may participate in one of the roles. A role-play is suitable for assessing problem-solving and strategic skills. Learners may be self-conscious and react differently from the real situation. The case study can be difficult to write, and requires a very good understanding of the situation itself. Case studies need credibility to be effective. 


\subsection{Journals or log-books}

These are kept by learners who report on processes as they occur. Journals are diaries that learners keep during the process of tasks, activities or jobs. Log-books are more structured and record or "log" when specific tasks or actions happen. Journals and logbooks are useful for assessing progress and monitoring changes. They provide opportunities for guidance and growth and are therefore very suitable for formative assessment. They are also useful for programme evaluation. Clear guidelines are necessary before starting. They require self-motivation. Reliability may also be an issue, since it is difficult to ensure that the record is accurate and true.

\subsection{Tests or examinations}

Tests or examinations are written responses to questions within tightly defined conditions and time-frames. While most examinations are without access to support material, take-home, or open-book examinations are possible. Tests or examinations are useful for large group assessment. They match most people's idea of what assessment is and can provide evidence of scope and knowledge. Real competencies may, however, be masked by poor examination skills. Testing or examining favours those with good writing skills and they assess theoretical knowledge rather than actual performance.

\section{Evidence in Assessment}

Needless to say, the assessor gathers evidence to make judgement. The Assessor will at this stage, apply the rule of evidence to make evaluation of evidence and make judgments. This is another stage of the assessment process; the assessor is evaluating the evidence gathered by the leaner. The assessor will deem the learner

A. Competent - if the evidence gathered has met all the specific outcomes and its related assessment criteria of the unit standard.

B. Not Yet Competent - if the evidence gathered does not meet the specific outcome and criteria or more evidence is required. The feedback must be relevant and constructive. Further assessment will require that the learner be reassessed against the outstanding specific outcomes and criteria. This allows the learner to close gaps.

Evidence in assessment is a demonstrated proof of competence. It must therefore be:

- Valid: meet the specific outcomes and its related assessment criteria i.e. fit for purpose

- Authentic: created by the learner/ is the learner's work not anyone else

- Consistent/Reliable: the evidence will give the same results about the learner's competence either by different Assessors or over a period of time

- Current: the evidence applies to the latest version of the standard or reflect current practises

- Sufficient: evidence covers all the specific outcomes and criteria and the learner can demonstrate competency at an acceptable level

\subsection{Types of evidence}

The best type of evidence is that which can be observed directly by the Assessor. This means that evidence must be collected from activities that are as similar as possible to actual conditions. However, there are other types of evidence that are also valid if checked and verified. There are three main types of evidence:

\subsubsection{Direct evidence}

Direct evidence is actual evidence produced by the learner. This is the most valid type of evidence. Direct evidence also easily establishes authenticity. This should be the Assessor's primary source of evidence. Direct evidence includes: Direct observation of tasks, activities, etc; Questioning i.e. written / oral; Product and output evaluation. It may be necessary to verify evidence for example, a written assignment or product to ensure that it is the learner's own work

\subsubsection{Indirect evidence}

Indirect evidence is evidence produced about the learner from another source. This usually in the form of reports of third 
party sources i.e. sources other than that of the Assessor, indirect evidence can be used to verify the authenticity of other forms of evidence. In addition it may be necessary to corroborate these forms of evidence. Sources of indirect evidence include:

- Team outputs

- Work completed at an earlier stage

- Performance appraisal

- Training records

- Testimonials

- Reviews and commendations

- Certificates and qualifications

- Medals, prices and trophies

- Customer / client ratings

\subsubsection{Historical evidence}

This type of evidence tells the assessor what the learner was capable of doing in the past. It is the least valid form of evidence because it does not necessarily prove current competence. Historical evidence usually needs to be checked for authenticity, the Assessor should guard against discrepancies on this kind of evidence but it is still a useful supplement to the assessment process more especially for Recognition of Prior Learning. Some examples of historical evidence are:

- Projects and Portfolios

- Video/audio taped performance/ photographs

- Document competed by the learner

- Performance appraisal

- Training records

- Testimonials

- Review and commendations

- Certificates and qualification

- Medals, prices and trophies

- Customer or client ratings

\section{Conclusion}

The RPL provides an opportunity to the candidates to demonstrate their knowledge and skills. They have to undergo a series of assessments specifically designed to assist them to display their competence to a registered assessor. Through SAQA nationally-registered qualifications are awarded to the candidates who demonstrate that learning has taken place backed by evidence in a particular field. A candidate either earns credit for a few unit standards or a full qualification. RPL empowers mostly previously disadvantaged individuals by recognising any learning that they might have acquired, whether it was from formal training, workplace experience, or general life experience. RPL embraces lifelong learning by means of enabling people to learn at different times, in different ways, for different purposes at various stages of their lives and careers. Lifelong education is concerned with providing learning opportunities throughout life. However much still needs to be done by the employers, government and training providers to ensure that more people reap the RPL benefits in South Africa.

\section{References}

Adams, M., Bell, L.A., Griffen, P. (1997). Teaching for Diversity and Social Justice. Routledge: New York \& London.

Bellis, I. June (1997). Equity Issues in Education and Assessment. Outcomes-based Education: Issues of Competence and Equity in Curriculum and Assessment. South African Certification Council.

Centre for Educational Research, Evaluation \& Policy (CEREP) (1998). Outcomes-based Education: Perspectives, Policy, Practice and Possibilities. University of Durban-Westville: Durban.

Deller, K. (2007).Towards the design of a workplace RPL implementation model for the South African insurance sector. Unpublished PhD Thesis. Johannesburg: University of Johannesburg

Chase, C.I. (1999). Contemporary Assessment for Educators. Longman: New York. 
Cotton, J. (1995). The Theory of Assessment. Kogan Page: London.

Craig, R.L. (1993).Training Development Handbook. A Guide to Human Resource Development. 3rd Edition. McGraw-Hill Book Company: New York.

Desmond, C.T. 1996. Shaping the Culture of Schooling. State University of New York Press: New York.

ETDQA. (2004). Guidelines for assessment. ETDP SETA Publication.

Government Gazette (SA). Act no. 97 of 1998: Skills Development Act, 1998.

Freeman, R., \& Lewis, R. (1998). Planning and Implementing Assessment. Kogan Page: London.

Gronlund, N.E. 1998. Assessment of Learner Achievement. Allyn and Bacon: Boston.

Le Grange, L. and Reddy, C. (2000). Continuous Assessment. An Introduction and Guideline to Implementation. Juta: Kenwyn.

Malan, B. (1997). Excellence through Outcomes. Kagiso Publishers: Joahnnesburg.

Spady, W. and Schwahn, C. (1999). The Operating Essentials and Indicators of Total Learning Communities. A Concrete Vision for Education in the Information Age. Breakthrough Learning Systems.

Marzano, R.J. March (1994). Lessons from the Field about Outcomes-Based Performance Assessment. Educational Leadership.

Makole, K. (2010). Understanding Recognition of Prior learning in the context of organizational labour: Opportunities and Challenges: South African Democratic Teachers Union (SADTU).

Olivier C. (1999). Let's Educate, Train and Learn Outcomes-Based. A 3D Experience in Creativity. NQF Based Design Book: Published?: South Africa.

Pahad, M. (1998). Outcomes-based Assessment: The Need for a Common Vision of What Counts and How to Count It. University of Durban-Westville: Durban.

Raggatt, P. Cookwood, F. (1994). Materials Production in Open and Distance Learning. Paul Chapman Publishing: London.

South African Qualifications Authority(2000). The National Qualifications Framework: An Overview. SAQA Publication.

South African Qualifications Authority (1998). South African Qualifications Authority Bulletin. Volume 2, Number 31. 